\title{
Local Fatigue Strength Evaluation of Shot Peened 40Cr Notched Steel
}

\author{
Xiaohui Zhao ${ }^{1}$, Zhaoyi Sun ${ }^{1}$, Desheng $\mathrm{Xu}^{1}$ and $\mathrm{Yu} \mathrm{Liu}{ }^{2, *}$ \\ 1 Key Laboratory of Automobile Materials, School of Materials Science and Engineering, Jilin University, \\ Changchun 130025, China; zhaoxiaohui@jlu.edu.cn (X.Z.); sunzy16@mails.jlu.edu.cn (Z.S.); \\ xuds@jlu.edu.cn (D.X.) \\ 2 School of Mechanical and Aerospace Engineering, Jilin University, Changchun 130025, China \\ * Correspondence: liuyuu@jlu.edu.cn; Tel./Fax: +86-0431-8509-5316
}

Received: 30 July 2018; Accepted: 16 August 2018; Published: 29 August 2018

\begin{abstract}
Fatigue life prediction for the notched components is an essential step within the design process of machines. Fatigue strength and life prediction of $40 \mathrm{Cr}$ notched steel before and after shot peening were studied. Fatigue fracture of specimens treated by three shot peening intensity parameters was discussed. The life prediction considering residual stress, work hardening and surface roughness caused by shot peening was analyzed. The results indicated that fatigue strength was obviously improved after shot peening and the improvement effect was gradually enhanced with the increase of shot peening intensity. The predicted values based on $R_{\mathrm{z}}$ coefficient showed a good correspondence with the experimental data.
\end{abstract}

Keywords: shot peening; local stress; fatigue limit; stress gradient

\section{Introduction}

The assessment of fatigue strength is an important step in the design of engineering structures. Experimental design to determine the $S-N$ curves for different loads or different notched components will take a great deal of time and resources. Meanwhile, most of the existing fatigue assessments are limited to specific loading conditions and material properties change [1,2]. Therefore, it is difficult to apply original evaluation methods on materials after surface strengthening (such as shot peening). Shot peening technology can improve surface integrity of metal materials (surface roughness, residual stress, hardness, microstructure, etc.). The increase of surface roughness or even surface cracking caused by shot peening will seriously reduce the fatigue strength and life of materials [3,4]. However, surface residual compressive stress and surface hardening can suppress the initiation and extension of fatigue cracks, and these effects are very useful to prevent or delay component failure [5-7]. Although shot peening is considered as an effective means of significantly improving fatigue strength of materials, the law of the effect of shot peening on fatigue performance is still worth studying.

Eichlseder [8] introduced a method based on linear elastic finite element calculations of stress gradients for fatigue life assessment of the notched components. Some influencing factors of local fatigue limit of the notched fatigue specimen were analyzed. For example, as to some notched components, a certain degree of surface plastic deformation will occur during fatigue failure process. The plastic deformation zone is affected by stress gradient of the notch (see Figure 1). The Eichlseder's approach has been applied on the shot peening notched specimens by Bagherifard and Olmi et al. [9-12]. Combined with the effect of shot peening on the surface integrity of materials, the local fatigue limit prediction method considering the effects of stress gradient, residual stress, work hardening and surface roughness is established. 


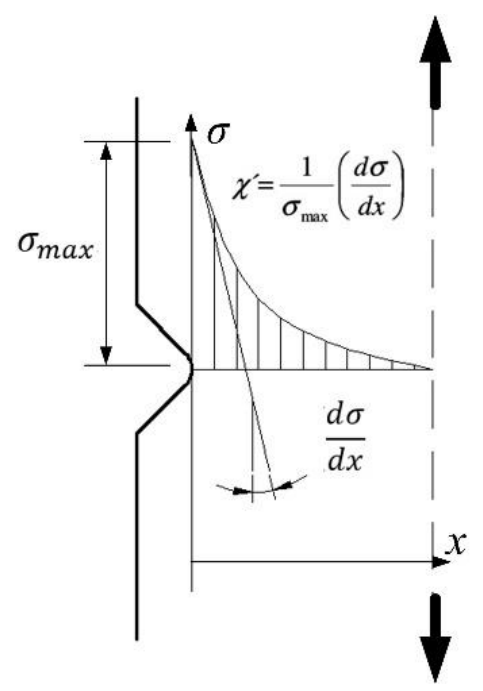

Figure 1. Stress gradient in notches caused by tension loading. Reproduced from [8], with copyright permission from Elsevier, 2002.

Yield strength, tensile strength, plasticity and toughness of the quenched and tempered $40 \mathrm{Cr}$ steel will be greatly improved after quenching and tempering. Therefore, it is often used to produce mechanical parts withstanding medium-load [13-15]. However, fatigue life of these parts is generally low under certain complex working conditions. In order to prolong the service life, surfaces of these parts usually need to be strengthened [16,17].

In this study, shot peening as a surface strengthening method was adopted to treat $40 \mathrm{Cr}$ steel. Fatigue fracture mechanism and life prediction method of the specimens treated by three shot peening intensity parameters were discussed.

\section{Experimental Procedures}

$40 \mathrm{Cr}$ steel (according to Chinese nomenclature), after oil quenching at $840{ }^{\circ} \mathrm{C}(25 \mathrm{~min})$ and tempering at $600{ }^{\circ} \mathrm{C}(2 \mathrm{~h})$, was used in the present study. Its chemical composition (in wt.\%) and mechanical properties are listed in Tables 1 and 2, respectively. Microstructure of 40Cr was observed by a Zeiss Scope Al type of optical microscope. As shown in Figure 2, the microstructure of quenched and tempered $40 \mathrm{Cr}$ is mainly tempering sorbite.

Table 1. The chemical composition of 40Cr steel.

\begin{tabular}{ccccccc}
\hline $\mathbf{C}$ & $\mathbf{S i}$ & $\mathbf{M n}$ & $\mathbf{C r}$ & $\mathbf{N i}$ & $\mathbf{P}$ & $\mathbf{S}$ \\
\hline $0.37 \sim 0.44$ & $0.17 \sim 0.37$ & $0.5 \sim 0.8$ & $0.8 \sim 1.1$ & $\leq 0.030$ & $\leq 0.035$ & $\leq 0.035$ \\
\hline
\end{tabular}

Table 2. The mechanical properties of $40 \mathrm{Cr}$ steel.

\begin{tabular}{cccc}
\hline Yield Strength (MPa) & Ultimate Tensile Strength (MPa) & Elongation Rate (\%) & HV \\
\hline 750 & 880 & 9.7 & 260 \\
\hline
\end{tabular}




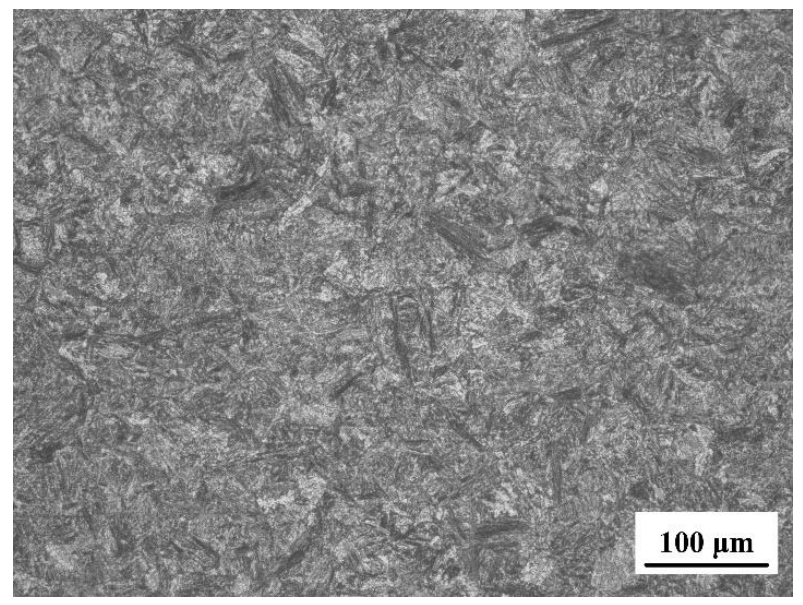

Figure 2. Microstructure of quenched and tempered $40 \mathrm{Cr}$ steel.

The geometrical shape and dimension of smooth and notched tensile fatigue specimen (the notch radius is $3 \mathrm{~mm}$ ) are shown in Figures 3 and 4, respectively. Figure 5 presents the geometrical characteristics of smooth rotating bending fatigue specimen and its diameter is $8 \mathrm{~mm}$.

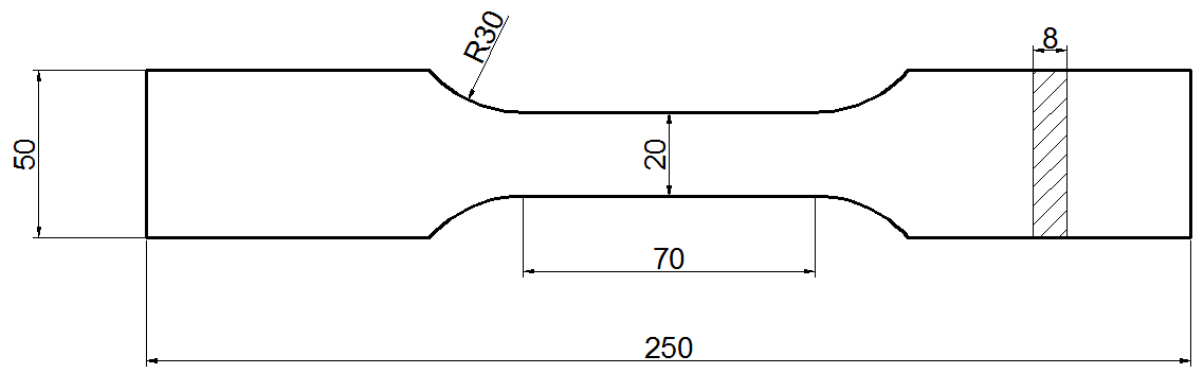

Figure 3. Geometry and dimension of smooth fatigue specimen.

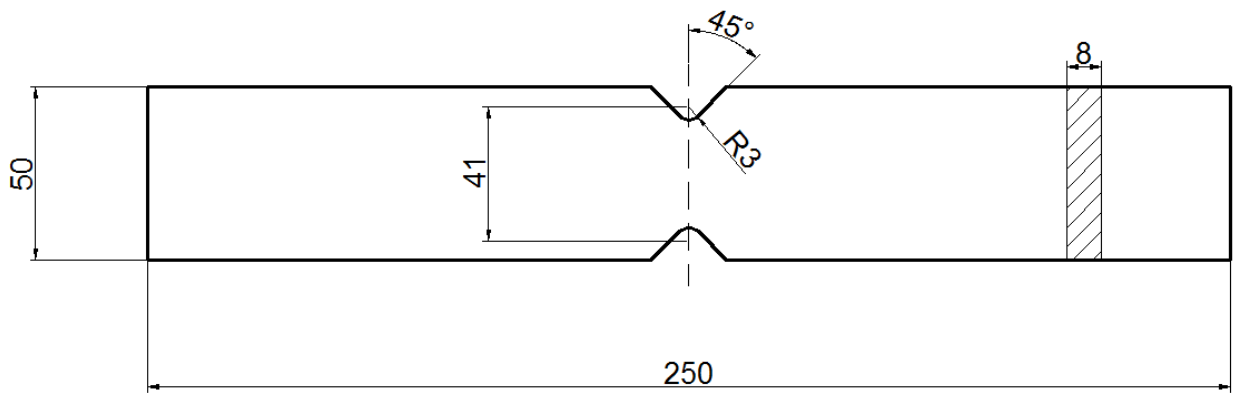

Figure 4. Geometry and dimension of notched fatigue specimen.

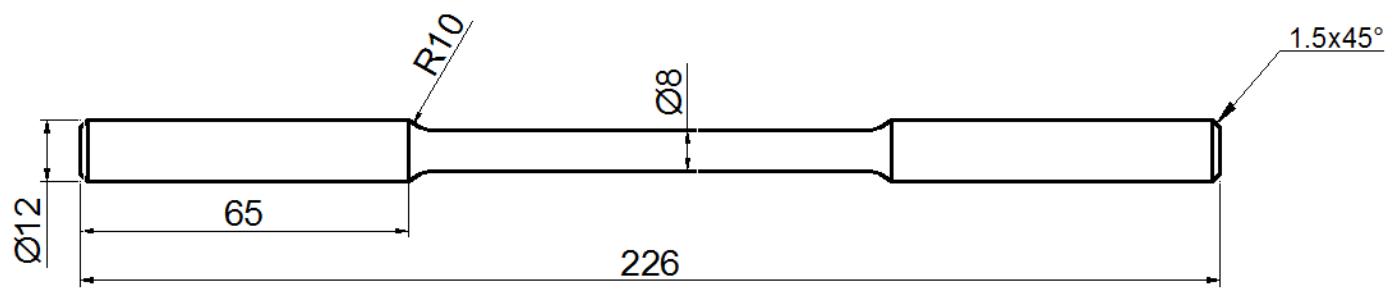

Figure 5. Geometry and dimension of smooth rotating bending fatigue specimen. 
The notched fatigue specimen was treated by a pneumatic shot blasting machine using the parameters listed in Table 3. The shot peening process was performed with spray angle of $90^{\circ}$ and coverage of $100 \%$.

Table 3. Shot peening (SP) parameters adopted for treating fatigue specimens.

\begin{tabular}{cccc}
\hline Treatment & Shot Type & Almen Intensity (mmA) & Coverage (\%) \\
\hline SP1 & S110 & 0.2 & 100 \\
SP2 & S110 & 0.3 & 100 \\
SP3 & S110 & 0.4 & 100 \\
\hline
\end{tabular}

Fatigue experiments of the non-peening and shot peening specimens were carried out on a high-frequency fatigue testing machine at room temperature. Figure 6 shows the fixture with fatigue specimen. Tension-tension cyclic loading with constant amplitude was applied on notched fatigue specimens (Figure 4 ) under stress ratio $(R)$ of 0.1 and smooth fatigue specimens (Figure 3 ) under stress ratio $(R)$ of -1 . Four-point bending fatigue test was carried out for smooth specimens (Figure 5) under stress ratio $(\mathrm{R})$ of -1 . The test frequency is $140 \mathrm{~Hz}$. All the tests proceeded until failure or at least $2 \times$ $10^{6}$ cycles (whichever arrived first).

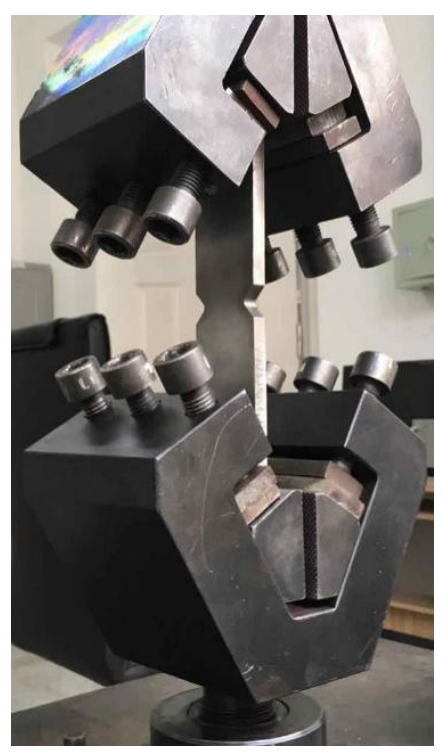

Figure 6. High-frequency fatigue testing fixture with specimen.

A Carl Zeiss EVO-18 type of scanning electron microscope (SEM, Carl Zeiss, Jena, Germany) was used to examine the changes in the cross sections of shot peening specimens and the fatigue fracture morphology. X-ray diffraction (XRD) patterns of specimens were obtained by using a D/max 2500 pc X-ray diffractometer (Science Corporation, Tokyo, Japan). Then, the XRD linear analysis was adopted to get the full width at half maximum of diffraction peak (FWHM), which is assumed as an index of work hardening of materials. The surface roughness of shot peening specimens was measured by an OLS3000 laser confocal microscope (Olympus Corporation, Tokyo, Japan). Five different locations on the specimen surface were detected to obtain the average value. Residual stress after shot peening was tested by a STRESS X3000 X-ray tester (Stresstech, Vaajakoski, Finland). The residual compressive stress was measured along the depth of shot peening specimens using the $\sin ^{2} \Psi$ method with $\mathrm{Cr}-\mathrm{K} \alpha$ radiation on the (211) plane, scanning step of $0.1^{\circ}, \Psi$ angles of $0.0^{\circ}$ and $45^{\circ}$, and stress constant $K$ of $-318 \mathrm{MPa} /\left(^{\circ}\right)$. The electrolytic polishing liquid was a mixed solution of $\mathrm{HCl}$ and $\mathrm{HNO}_{3}$ with the ratio of $3: 1$. 
In addition, the finite element software ABAQUS (6.13.1, Dassault SIMULIA, Providence, RI, USA) was used to simulate the stress field near the notch under nominal stress of $100 \mathrm{MPa}$. The model contained 61,100 nodes and 12,870 elements. The element type adopted was C3D20R. The Young modulus is $210 \mathrm{GPa}$, and the Possion ratio is 0.3 . Using the simulation results, the relative stress gradient of notched fatigue specimen can be calculated. Stress concentration factor was obtained as Equation (1):

$$
K_{t}=\frac{\sigma_{\max }}{\sigma_{m}}
$$

where $\sigma_{\text {max }}$ is the local stress at the notch and $\sigma_{m}$ is the nominal stress applied to the specimen. For the notched specimens, the stress concentration factor $\left(K_{t}\right)$ is 2.88 .

\section{Results and Discussion}

\subsection{Fatigue Properties}

\subsubsection{Effect of Shot Peening on Fatigue Strength}

High-cycle tension-tension fatigue tests were performed following the staircase procedure. Fifteen specimens and four stress levels were used for each parameter in fatigue tests, and the staircase stress was $10 \mathrm{MPa}$. Fatigue limits were calculated by nominal stress. Then, these loads were converted into local stresses at the root of the notch. The local fatigue strength of non-peening (NP), SP1, SP2 and SP3 specimens is $625 \mathrm{MPa}, 714 \mathrm{MPa}, 740 \mathrm{MPa}$ and $763 \mathrm{MPa}$, respectively, corresponding to 2 million cycles. Figure 7 presents $S-N$ curves of notched specimen characterized by nominal stress under high stress. Clearly, fatigue strength was obviously improved after shot peening. Meanwhile, the improvement effect was enhanced with the increase of shot peening intensity (see Figure 8). The improve of fatigue strength of shot peening specimens is mainly caused by the work-hardening and residual compressive stress generated by shot peening.

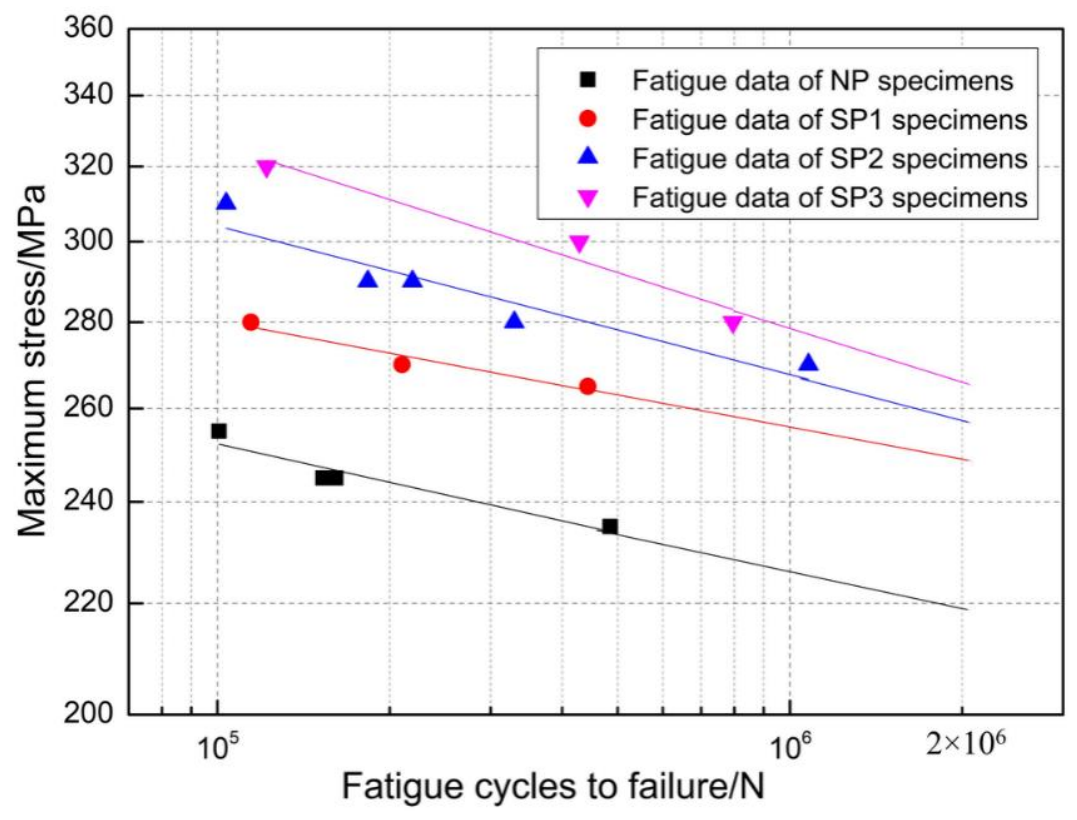

Figure 7. Fatigue data and $S-N$ curves of NP, SP1, SP2 and SP3 specimens. 


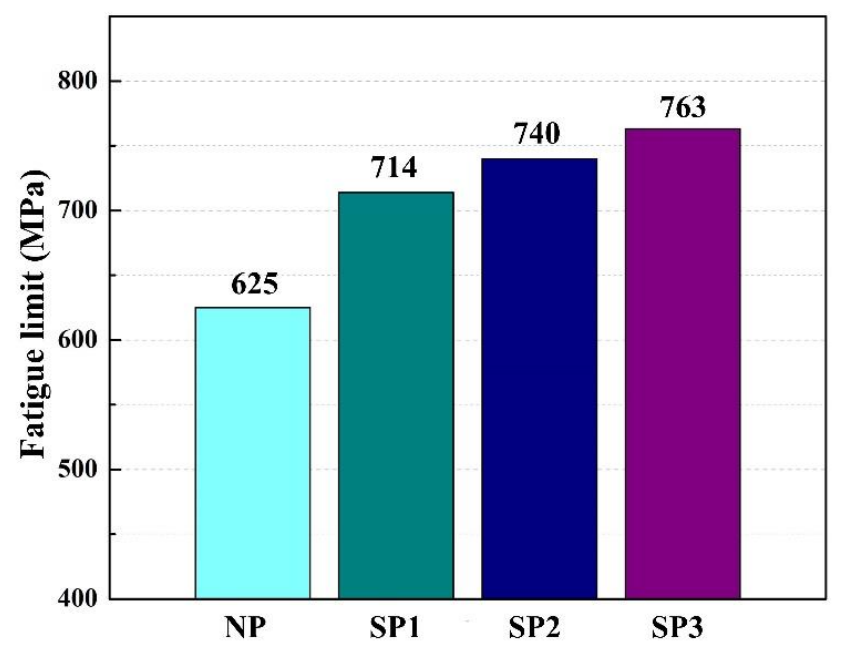

Figure 8. Local fatigue limit of the notched specimens (2 million).

Figure 9 shows the cross-sectional SEM observation of shot peening specimens. From the overall view, a distinct darker region is easily recognized near the top surface. This is because shot peening produces work hardening effect on the surface of specimen. Plastic deformation occurs on the surface, and the density of tissue is improved. The refinement of microstructure in surface hinders crack propagation and increases fatigue life. The thickness of work hardening layer corresponding to SP1, SP2 and SP3 specimen is $80 \mu \mathrm{m}, 140 \mu \mathrm{m}$ and $200 \mu \mathrm{m}$, respectively. The depth of work hardening layer increases with the increase of shot peening intensity.
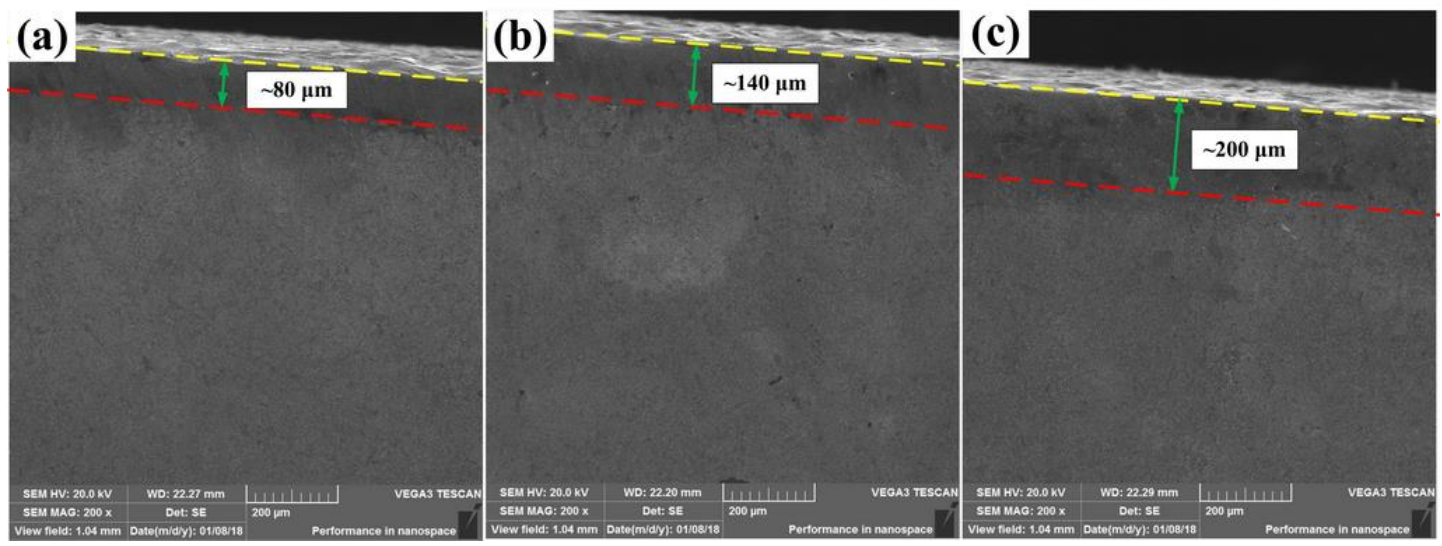

Figure 9. The cross-sectional scanning electron microscope (SEM) observation of shot peening specimens: (a) SP1 specimen; (b) SP2 specimen; (c) SP3 specimen.

It is known that residual compressive stress can reduce the crack growth rate [18-20]. Figure 10 shows the distribution of residual stress along the depth of specimens under shot peening intensity of $0.2 \mathrm{mmA}, 0.3 \mathrm{mmA}$ and $0.4 \mathrm{mmA}$. As can be observed, the residual compressive stress value in the topmost surface under different shot peening parameters is $-622 \mathrm{MPa},-674 \mathrm{MPa}$ and $-658 \mathrm{MPa}$, respectively. The maximum residual compressive stress is found to be approximately $50 \mu \mathrm{m}$ below the treated surface. With the increase of shot-peening intensity, the maximum residual stress value gradually increases. 


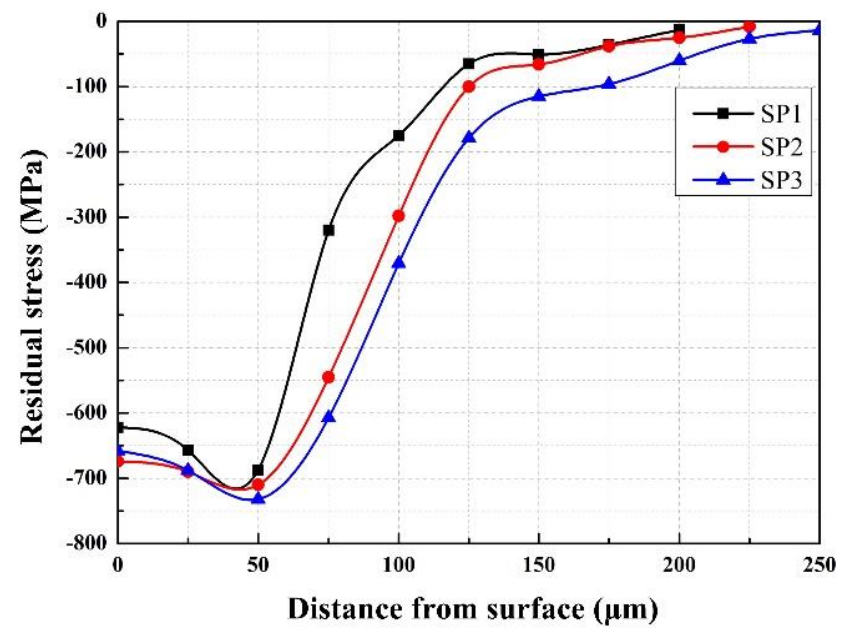

Figure 10. Residual stress distribution of the shot-peening specimens.

In addition, surface roughness is also a factor influencing fatigue strength. Figure 11 shows the surface morphologies obtained under different shot peening parameters. With the increase of shot peening intensity, the surface morphology is gradually worsened. Therefore, the increasing effect of fatigue strength gets slower.
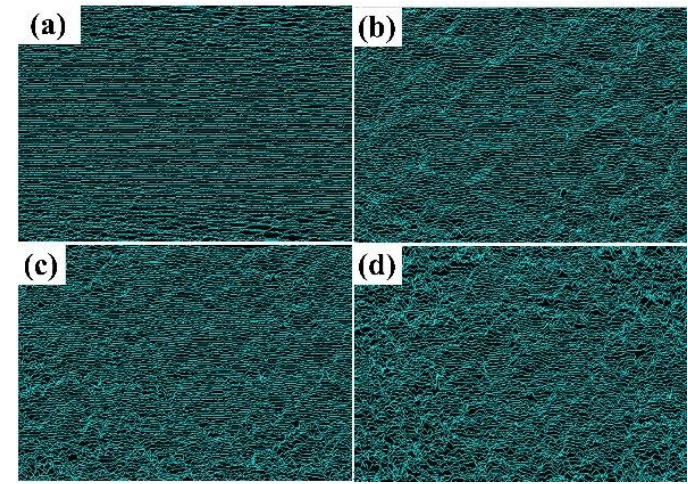

Figure 11. Surface morphology of specimens before and after shot peening: (a) NP specimen; (b) SP1 specimen; (c) SP2 specimen; (d) SP3 specimen.

\subsubsection{Fatigue Fracture Analysis}

Figure 12 shows the fatigue fracture of the NP specimen. It can be seen from Figure 12a that the crack source apparently initiates from the outer surface. Figure $12 b, c$ show the details of crack propagation zone, while the location of Figure $12 \mathrm{~b}$ is closer to the crack source than that of Figure 12c. Clearly, the fracture facet in Figure $12 b$ is small and the crack growth rate is relatively slow. Yet, in Figure 12c, the fracture facet is larger and fatigue striations can be observed on some fractured facets. Fatigue striation is formed by the alternation of each stress cycle during the fatigue test, and the crack propagation is rapid in this zone, which is close to the fracture zone. Figure 12d shows the fracture zone, where the boundary between the crack growth zone and fracture zone can be clearly observed. 

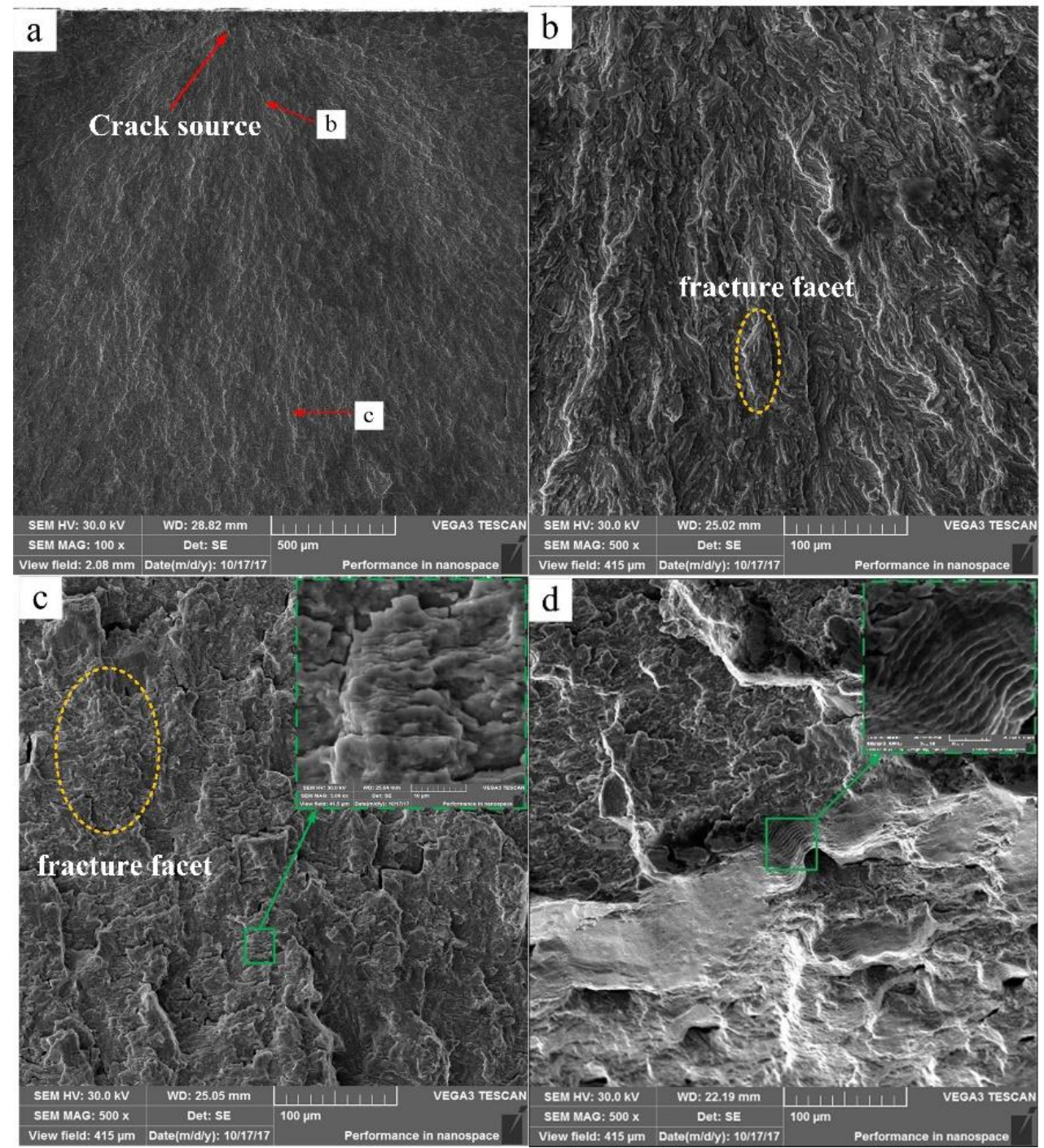

Figure 12. SEM images of the fracture surface of the NP specimen: $(\mathbf{a})$ crack source zone $(\mathbf{b}, \mathbf{c})$ crack propagation zone $(\mathbf{d})$ fracture zone.

Figure 13 shows the fatigue fracture morphologies of NP, SP1, SP2 and SP3 specimens. It can be found that fracture surface of NP specimen is relatively flat and crack source is single by comparison. After shot peening, the notched specimens have more crack sources. The number of crack source increases with the increase of shot peening intensity. Through the previous analysis, surface roughness was improved after shot peening, which will cause more serious stress concentration. Crack source will be easily formed at the location of stress concentration. Therefore, the number of crack sources will be increased. With the increase of crack sources, the area of each crack source region is decreased compared with that of single crack source region. 


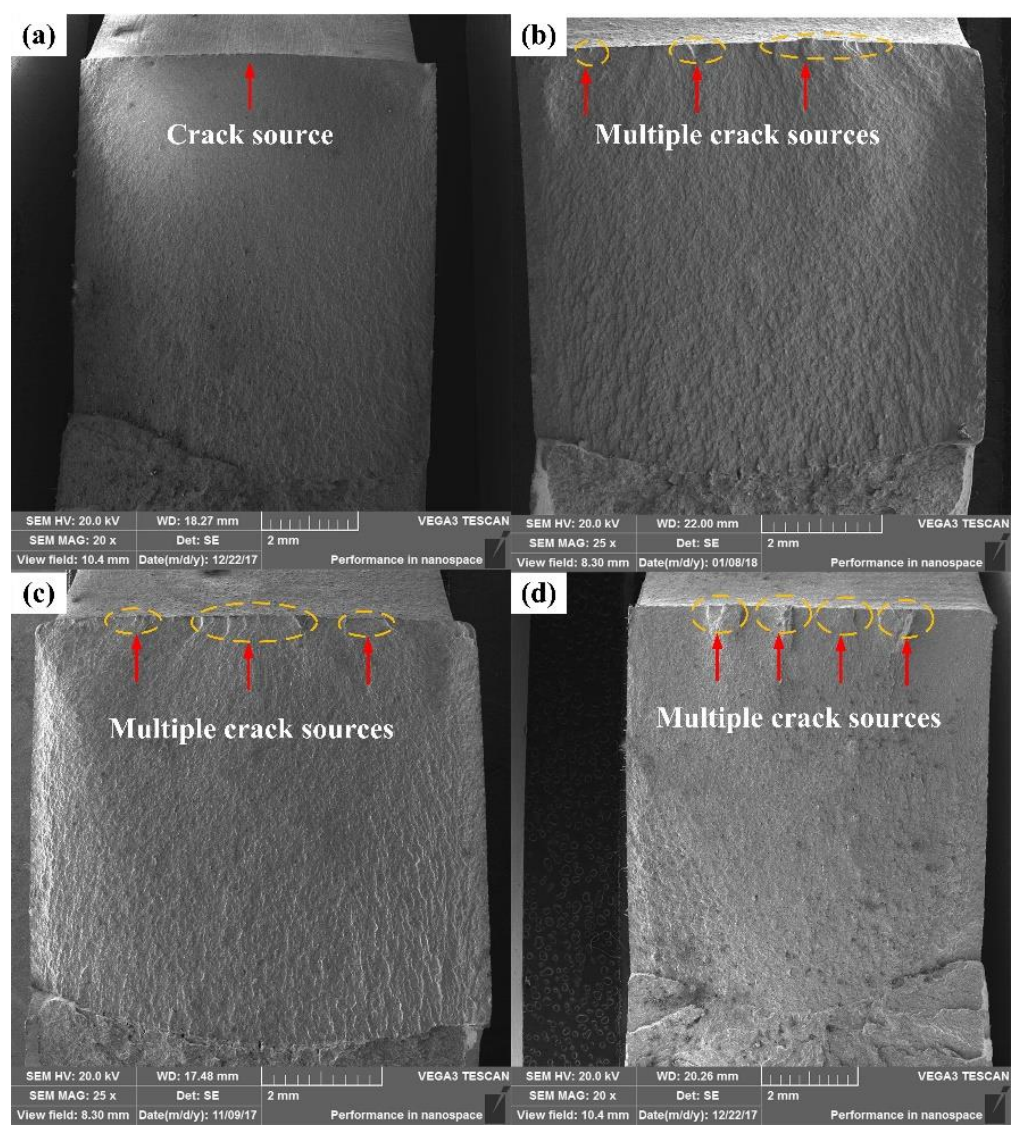

Figure 13. SEM images of fracture surfaces of the notched specimens: (a) crack source zone of NP specimen; (b) crack source zone of SP1 specimen; (c) crack source zone of SP2 specimen; (d) crack source zone of SP3 specimen.

\subsection{Local Fatigue Strength Evaluation}

Eichlseder [8] introduced a stress gradient method for fatigue life assessment of notched specimen based on the linear elastic finite element method. Using this method, the local fatigue limit of any notched (stress gradient) specimen can be effectively evaluated. The exponential relationship between fatigue limit and stress gradient as a function of relative stress gradient (RSG) is shown in Figure 1, Equations (2) and (3). The exponent $K_{D}$, which reflects the characteristic of material, describes how $\sigma_{f}$ behaves between $\sigma_{b f}$ and $\sigma_{t f} . K_{D}$ can be assumed to be 0.3 for alloyed steel materials [10]. $\sigma_{b f}$ is the bending fatigue limit and $\sigma_{t f}$ is the fatigue limit in uniform stress loading conditions of smooth specimens (Figures 3 and 5). The value of $\sigma_{b f}$ and $\sigma_{t f}$ is $520 \mathrm{MPa}$ and $377 \mathrm{MPa} . b$ is the thickness (or diameter) of fatigue specimen. RSG can be obtained through Equation (3). The calculated limit must be adjusted according to different $\mathrm{R}$ values. Considering the effect of the actual average stress of the cycle, the Haigh diagram (Goodman linear model) can be constructed [11].

$$
\begin{gathered}
\sigma_{f}=\sigma_{t f}\left[1+\left(\frac{\sigma_{b f}}{\sigma_{t f}}-1\right)\left(\frac{\chi^{\prime}}{2 / b}\right)^{K_{D}}\right] \\
\chi^{\prime}=\left(\frac{1}{\sigma_{\max }}\right)\left(\frac{\mathrm{d} \sigma}{d x}\right)
\end{gathered}
$$

RSG was calculated through finite element simulation. Figure 14 shows the stress distribution at the root of notched specimens before shot peening. The relative stress gradient under external load $\left(\sigma_{t f}\right)$ can be obtained by Equation (3). The $\sigma_{\max }$ is $1085 \mathrm{MPa}$ and the value of RSG is 0.36 . 


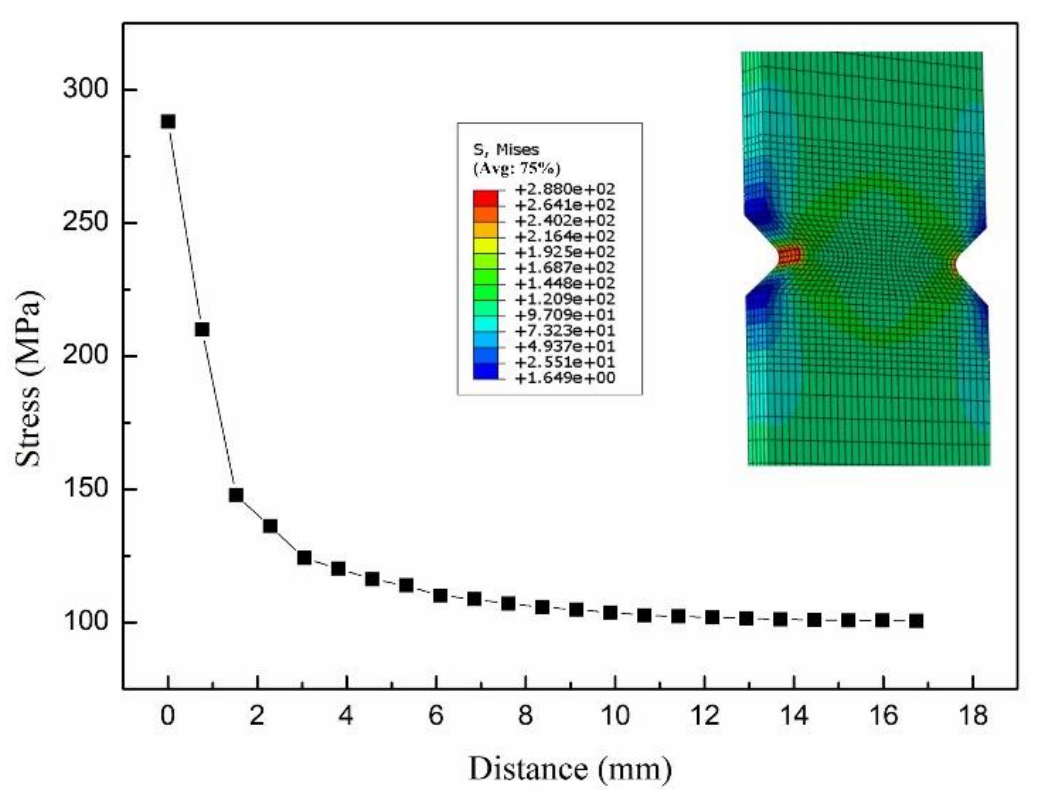

Figure 14. Stress distribution of notched specimen before shot peening.

However, for the prediction of fatigue strength after shot peening, the Eichlseder's method was modified by Bagherifard $[9,10]$. After shot peening, the effective stress distribution at the notch is the sum of the external load at its maximum value and residual compressive stress (Figure 10) generated by shot peening [11]. RSG of SP1, SP2 and SP3 specimens considering residual compressive stress is $2.96,2.46$ and 3.77 , respectively.

It can be seen from Figure 9 that the work hardening layer (deformed layer) was obtained. According to the modified equation put forward by Bagherifard and Fernandez Pariente [10,21], FWHM can be used to evaluate hardening effect of materials after shot peening treatment. Figure 15 shows the XRD spectrums of NP and SP specimens, from which FWHM values can be obtained. FWHM of NP specimen is 0.305 , while the FWHM value (see Figure 14) of fatigue specimen under SP1, SP2 and SP3 is $0.325,0.356$ and 0.375 . On the basis of Eichlseder's method [8], the local fatigue strengths were calculated through applying a work hardening coefficient introduced by Fernandez-Pariente and Guagliano [21]. This work hardening coefficient is calculated as the ratio of FWHM for peened specimen to that for the NP one. This modification takes into account the surface strain hardening index of FWHM obtained from XRD analysis [10]. Thus, the local fatigue strength of SP1, SP2 and SP3 specimens considering FWHM coefficient is $801 \mathrm{MPa}, 827 \mathrm{MPa}$ and $871 \mathrm{MPa}$, respectively. Compared with the actual testing values in Figure 8, the error is $12.2 \%, 11.8 \%$ and $14.2 \%$, respectively. The reason for the large error is that roughness changes were not considered in the calculation process. Bagherifard [10] introduced the surface roughness coefficient $\left(C_{s}\right)$ for evaluating the local fatigue limit according to the surface coefficient diagrams provided by Buch [22], which improved the prediction accuracy. 

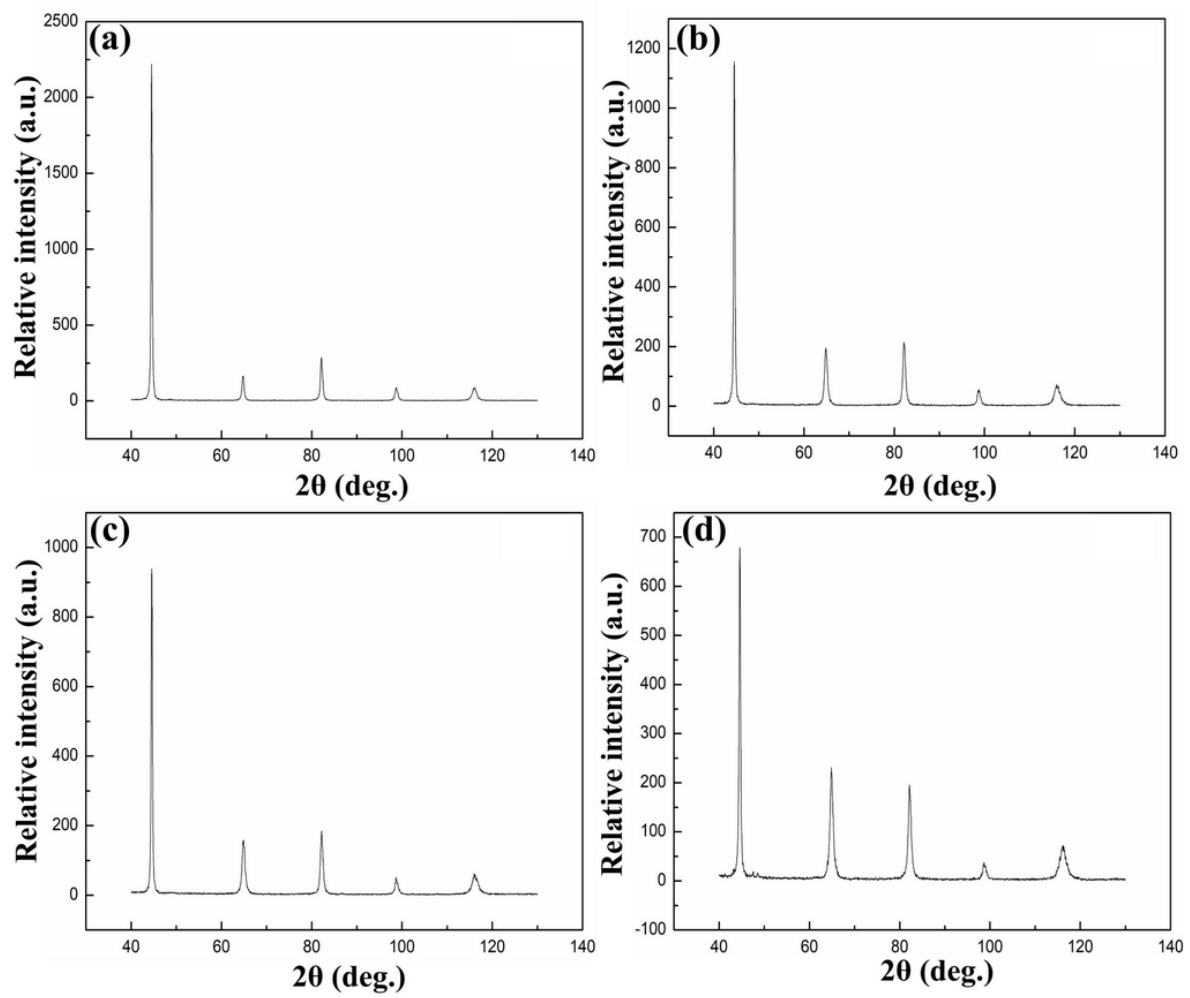

Figure 15. The $X$-ray diffraction $(X R D)$ spectrums of non-shot peening and shot peening specimens: (a) NP specimen; (b) SP1 specimen; (c) SP2 specimen; (d) SP3 specimen.

By analyzing the three-dimensional morphology of specimen surface (Figure 16), the surface roughness of NP and SP notched specimens can be obtained. The averages of obtained results are presented in Table 4. It can be clearly seen that all shot peened series have relatively high surface roughness values.

Table 4. Surface roughness of notched specimens.

\begin{tabular}{cccc}
\hline Specimen & $\boldsymbol{R}_{\boldsymbol{a}}$ & $\boldsymbol{R}_{\boldsymbol{z}}$ & $\boldsymbol{R}_{\boldsymbol{q}}$ \\
\hline NP & 1.887 & 60.021 & 2.451 \\
SP1 & 2.747 & 98.082 & 3.746 \\
SP2 & 2.911 & 100.216 & 4.013 \\
SP3 & 3.133 & 117.381 & 4.335 \\
\hline
\end{tabular}

From Table 4 , the $\sqrt{\frac{R_{\mathrm{ZNP}}}{R_{\mathrm{ZSP}}}}$ value and local fatigue strength considering $\sqrt{\frac{R_{\mathrm{ZNP}}}{R_{\mathrm{ZSP}}}}$ coefficient were calculated for three types of shot peening specimens (see Table 5). It is found that $\sqrt{\frac{R_{\mathrm{ZNP}}}{R_{\mathrm{ZSP}}}}$ can be used to modify the local fatigue limit for the $40 \mathrm{Cr}$ steel after oil quenching at $840{ }^{\circ} \mathrm{C}$ and tempering at $600{ }^{\circ} \mathrm{C}$, and the modified result is generally accurate when $R_{\mathrm{Z}}$ is in the range of 50-150 $\mu \mathrm{m}$.

Table 5. Predictive value vs. experimental value.

\begin{tabular}{cccc}
\hline Specimen & Calculated Fatigue Limit (MPa) & Experimental Data (MPa) & Error\% \\
\hline SP1 & 703 & 714 & -1.5 \\
SP2 & 726 & 740 & -1.9 \\
SP3 & 738 & 763 & -3.4 \\
\hline
\end{tabular}



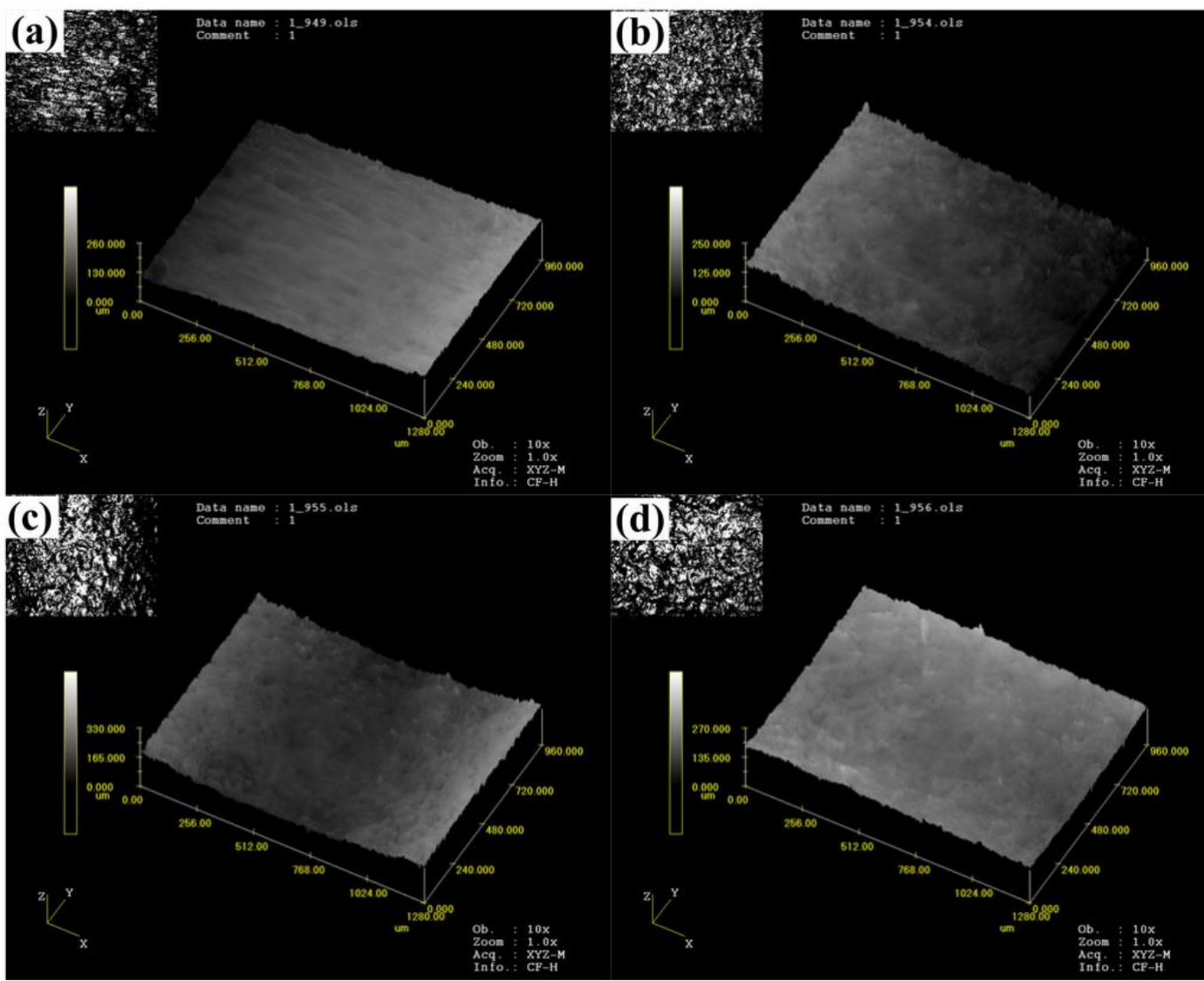

Figure 16. Three-dimensional morphology of specimens before and after shot peening: (a) NP specimen; (b) SP1 specimen; (c) SP2 specimen; (d) SP3 specimen.

\section{Conclusions}

Fatigue strength and life prediction of $40 \mathrm{Cr}$ notched steel before and after shot peening were studied. The conclusions are as follows:

(1) Shot peening produces work hardening effect on the surface of specimen. Plastic deformation occurs in the surface, and leads to a more compact microstructure. The variation of maximum residual stress under different shot peening intensity is small. Surface roughness is increased with the increase of shot peening intensity.

(2) Fatigue limit of notched specimens treated by three types of shot peening paraments was increased from $14.2 \%$ to $22.1 \%$ under the combined effect of working hardening, residual stress and surface roughness produced by shot peening.

(3) The local fatigue limit was decided by residual stress, work hardening and surface roughness. In this study, $R_{z}$ coefficient was directly used to characterize the effect of surface roughness on fatigue properties and satisfactory results were obtained for local fatigue limit prediction of shot peening specimens.

Author Contributions: Conceptualization, Y.L. and D.X.; Methodology, X.Z.; Software, Z.S.; Validation, X.Z., D.X. and Y.L.; Formal Analysis, X.Z.; Investigation, X.Z.; Resources, D.X.; Data Curation, Z.S.; Writing-Original Draft Preparation, X.Z.; Writing-Review \& Editing, Y.L.; Visualization, Z.S.; Supervision, D.X.; Project Administration, X.Z.; Funding Acquisition, X.Z.

Funding: This research was funded by the Natural Science Foundation of Jilin province, the grant number is 20180101323JC. 
Conflicts of Interest: The authors declare no conflict of interest. The funders had no role in the design of the study; in the collection, analyses, or interpretation of data; in the writing of the manuscript, and in the decision to publish the results.

\section{References}

1. Schulze, V. Modern Mechanical Surface Treatment, States, Stability, Effects; John Wiley \& Sons: New York, NY, USA, 2006; pp. 247-319.

2. Liu, G.; Wang, S.C.; Lou, X.F.; Lu, J.; Lu, K. Low carbon steel with nanostructured surface layer induced by high-energy shot peening. Scr. Mater. 2001, 44, 1791-1795. [CrossRef]

3. Abrão, A.M.; Aspinwall, D.K. The surface integrity of turned and ground hardened bearing steel. Wear 1996, 196, 279-284. [CrossRef]

4. Guilhem, Y.; Basseville, S.; Curtit, F.; Stéphan, J.; Cailletaud, G. Numerical analysis of the effect of surface roughness on mechanical fields in polycrystalline aggregates. Model. Simul. Mater. Sc. 2018, 26, 045004. [CrossRef]

5. Nascimento, M.P.; Souza, R.C.; Pigatin, W.L.; Voorwald, H.J.C. Effects of surface treatments on the fatigue strength of AISI 4340 aeronautical steel. Int. J. Fatigue 2001, 23, 607-618. [CrossRef]

6. Zhang, X.; Liu, D. Effect of shot peening on fretting fatigue of Ti811 alloy at elevated temperature. Int. J. Fatigue 2009, 31, 889-893. [CrossRef]

7. Zhang, Z.; Song, Y.; Wu, H.; Du, S.S.; Shen, G.; Wu, W.Y.; Lu, K.; Wei, J.; Readman, P.; Peñate, J.; et al. Fatigue tests on ITER PF6 Coil Helium Inlet at 77K. IEEE T. Appl. Supercon. 2018, 28, 1-7. [CrossRef]

8. Eichlseder, W. Fatigue analysis by local stress concept based on finite element results. Comput. Struct. 2002, 80, 2109-2113. [CrossRef]

9. Bagherifard, S.; Colombo, C.; Guagliano, M. Application of different fatigue strength criteria to shot peened notched components. Part 1: Fracture Mechanics based approaches. Appl. Surf. Sci. 2014, 289, 180-187. [CrossRef]

10. Bagherifard, S.; Guagliano, M. Application of different fatigue strength criteria on shot peened notched parts. Part 2: Nominal and local stress approaches. Appl. Surf. Sci. 2014, 289, 173-179. [CrossRef]

11. Olmi, G.; Comandini, M.; Freddi, A. Fatigue on Shot-Peened Gears: Experimentation, Simulation and Sensitivity Analyses. Strain 2010, 46, 382-395. [CrossRef]

12. Olmi, G.; Freddi, A. A new method for modelling the support effect under rotating bending fatigue: Application to Ti-6Al-4V alloy, with and without shot peening. Fatigue Fract. Eng. Mater. 2013, 36, 981-993. [CrossRef]

13. Zhao, L.H.; Feng, J.Z.; Zheng, S.L. Effect of Cyclic Stresses Below the Endurance Limit on the Fatigue Life of 40Cr Steel. Strength Mater. 2018, 50, 2-10. [CrossRef]

14. Zhao, X.H.; Zhao, B.; Liu, Y.; Cai, Y.; Hu, C.H. Research on friction and wear behavior of gradient nano-structured 40Cr steel induced by high frequency impacting and rolling. Eng. Fail. Anal. 2017, 83, 167-177. [CrossRef]

15. Wu, G.C.; Li, Y.F.; Pan, X.D; Wang, G.L. Numerical simulation of fatigue damage and shape instability behavior of steel 40Cr by the damage-coupled crystal plastic model. Strength Mater. 2017, 49, 118-124. [CrossRef]

16. Gao, Y.K. Fatigue limit of chemical heat treated specimens and effect of shot peening. Surf. Eng. 2013, 24, 322-326. [CrossRef]

17. Liu, Y.; Zhao, X.; Wang, D. Effective FE model to predict surface layer characteristics of ultrasonic surface rolling with experimental validation. Mater. Sci. Technol. 2014, 30, 627-636. [CrossRef]

18. Fathallah, R.; Laamouri, A.; Sidhom, H.; Braham, C. High cycle fatigue behavior prediction of shot-peened parts. Int. J. Fatigue 2004, 26, 1053-1067. [CrossRef]

19. Song, P.S.; Wen, C.C. Crack closure and crack growth behaviour in shot peened fatigued specimen. Eng. Fract. Mech. 1999, 63, 295-304. [CrossRef]

20. Kashaev, N.; Ventzke, V.; Horstmann, M.; Chupakhin, S.; Riekehr, S.; Falck, R.; Maawad, E.; Staron, P.; Schell, N.; Huber, N. Effects of laser shock peening on the microstructure and fatigue crack propagation behaviour of thin AA2024 specimens. Int. J. Fatigue 2017, 98, 223-233. [CrossRef] 
21. Pariente, I.F.; Guagliano, M. About the role of residual stresses and surface work hardening on fatigue $\Delta \mathrm{Kth}$ of a nitrided and shot peened low-alloy steel. Surf. Coat. Technol. 2008, 202, 3072-3080. [CrossRef]

22. Buch, A. Fatigue Strength Calculation; Transtech Publications: Zürich, Switzerland, 1988; pp. 51-54.

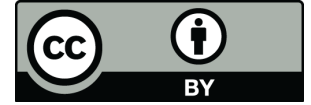

(C) 2018 by the authors. Licensee MDPI, Basel, Switzerland. This article is an open access article distributed under the terms and conditions of the Creative Commons Attribution (CC BY) license (http://creativecommons.org/licenses/by/4.0/). 